\title{
Primary intracranial aggressive fibromatosis arising in sella turcica: illustrative case
}

Kenta Ujifuku, MD, PhD, ${ }^{1}$ Eisakua Sadakata, MD, ${ }^{2}$ Shiro Baba, MD, PhD, ${ }^{2}$ Koichi Yoshida, MD, ${ }^{2}$ Kensaku Kamada, MD, PhD, ${ }^{1}$ Minoru Morikawa, MD, PhD, ${ }^{3}$ Kuniko Abe, MD, PhD, ${ }^{4}$ Kazuhiko Suyama, MD, PhD, ${ }^{2}$ Yoichi Nakazato, MD, PhD, ${ }^{5}$

Isao Shimokawa, MD, $\mathrm{PhD},{ }^{6}$ and Takayuki Matsuo, $\mathrm{MD}, \mathrm{PhD}^{1,2}$

\begin{abstract}
${ }^{1}$ Department of Neurosurgery, Nagasaki University Graduate School of Biomedical Sciences, Nagasaki, Japan; ${ }^{2}$ Department of Neurosurgery, Nagasaki University Hospital, Nagasaki, Japan; ${ }^{3}$ Department of Radiology, Nagasaki University Graduate School of Biomedical Sciences, Nagasaki, Japan; ${ }^{4}$ Department of Pathology, Nagasaki University Hospital, Nagasaki, Japan; ${ }^{5}$ Department of Human Pathology, Graduate School of Medicine, Gunma University, Gumma, Japan; and ${ }^{6}$ Department of Pathology, Graduate School of Biomedical Sciences, Nagasaki University, Nagasaki, Japan
\end{abstract}

BACKGROUND Aggressive fibromatosis is a rare histologically benign but locally infiltrative myofibroblastic tumor. Primary intracranial aggressive fibromatosis (IAF) can exhibit a clinically malignant course.

OBSERVATIONS A 22-year-old otherwise healthy woman presented with left painful ophthalmoplegia. Magnetic resonance imaging (MRI) revealed a left sellar tumor with cavernous sinus invasion. Endoscopic transsphenoidal surgery was performed. The lesion could not be totally resected. An inflammatory myofibroblastic tumor was suspected, so steroid pulse therapy was introduced, but it was ineffective. The tumor recurred after a few months, and she complained of visual acuity loss, abducens nerve palsy, trigeminal neuralgia, and panhypopituitarism. The lesion was diagnosed as primary IAF by a pathological review. Gamma Knife radiosurgery was performed, and chemotherapies were introduced but ineffective. Her consciousness was disturbed, and MRI showed hypothalamic invasion of the tumor, occlusion and stenosis of carotid arteries, and cerebral stroke. Palliative care was introduced, and she died 32 months after the onset. The autopsy revealed tumor invasion to the cavernous sinus, optic nerve, hypothalamus, pituitary, and tonsillar herniation due to massive cerebral stroke.

LESSONS Radical resection can be impossible in patients with IAF. Radiotherapy and chemotherapy are not always effective for residual lesions. Adjuvant therapy for IAF remains to be explored.

https://thejns.org/doi/abs/10.3171/CASE21396

KEYWORDS intracranial aggressive fibromatosis; nonsteroidal anti-inflammatory drugs; radiosurgery; sella turcica; tamoxifen; transsphenoidal surgery

Aggressive fibromatosis is a rare myofibroblastic tumor also known as desmoid tumor, infantile/juvenile fibromatosis, desmoid fibromatosis, deep fibromatosis, grade 1 fibrosarcoma (desmoid type), desmoma, and desmoplastic fibroma of the bone. ${ }^{1,2}$ It is a histologically benign tumor with no metastatic potential but is locally infiltrative. ${ }^{3}$ Primary intracranial aggressive fibromatosis (IAF) is described as desmoid-type fibromatosis (International Classification of Diseases for Oncology code 8821/1) in the World Health Organization classification of central nervous system tumours. ${ }^{4}$ Most patients with aggressive fibromatosis have sporadic cases; they are predominantly female; and their cases are reported to be characterized by a mutation of the catenin $\beta 1$ (CTNNB1) gene..$^{5,6}$ The lesions tend to arise in the extraabdominal soft tissue, including the limbs, body trunk, and head and neck regions. Abdominal aggressive fibromatoses tend to be observed in patients with familial adenomatoid polyposis (FAP), which suggests that adenomatous polyposis coli pathway abnormalities can cause

ABBREVIATIONS CTNNB1 = catenin $\beta 1$ gene; FAP = familial adenomatoid polyposis; IAF = primary intracranial aggressive fibromatosis; ICA = internal carotid artery; $\mathrm{MRI}=$ magnetic resonance imaging; NSAID = nonsteroidal anti-inflammatory drug; SMA = smooth muscle actin; TKI = tyrosine kinase inhibitor; T1WI = T1-weighted imaging; T2WI = T2-weighted imaging.

INCLUDE WHEN CITING Published September 20, 2021; DOI: 10.3171/CASE21396.

SUBMITTED July 12, 2021. ACCEPTED July 20, 2021.

(C) 2021 The authors, CC BY-NC-ND 4.0 (http://creativecommons.org/licenses/by-nc-nd/4.0/). 

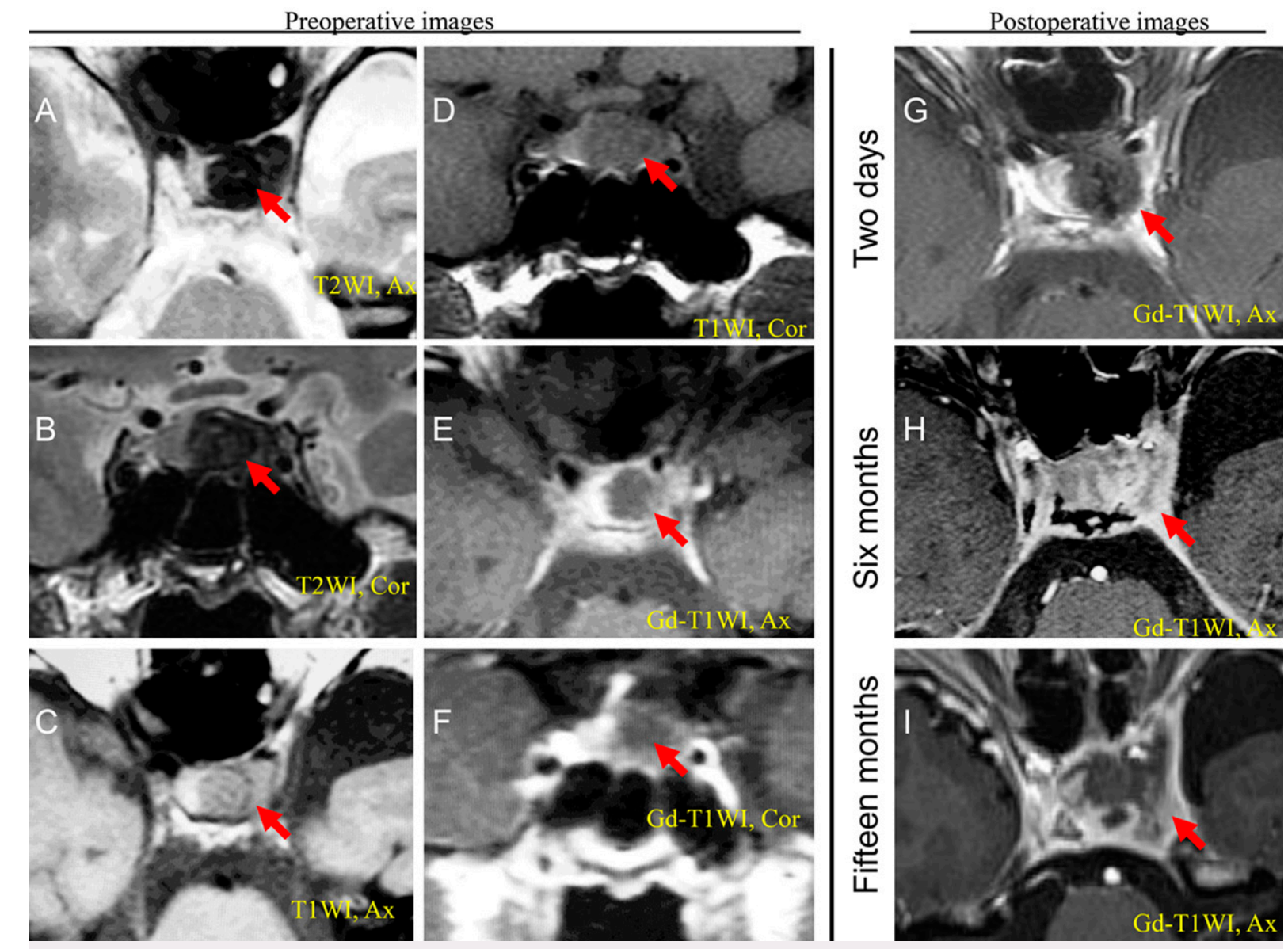

FIG. 1. Preoperative MRI. Red arrows indicate the corresponding tumor. A: Axial T2Wl showing tumor $15 \times 8 \mathrm{~mm}$ in size. B: Coronal T2WI. The tumor is markedly hypointense on T2WI. C: Axial T1WI. D: Coronal T1WI. The lesion is slightly hypointense on T1WI. E: Axial T1WI with gadolinium (Gd-T1WI). F: Coronal Gd-T1WI. No enhancement is found on the initial MRI. Postoperative MRI signal changes 2 days $(\mathbf{G}), 6$ months $(\mathbf{H})$, and 15 months (I) after surgery, respectively. Partial resection of the tumor is shown. Enhancement of the tumor is first found on the Gd-T1WI 6 months after, and ring enhancement is observed on the Gd-TIWI 15 months after surgery. Ax = axial image; Cor = coronal image.

nuclear accumulation of $\beta$-catenin and thereby lead to colon cancer and aggressive fibromatosis., ${ }^{5,6} \mathrm{IAF}$ is stated to occur on the dura mater $^{3,7}$ and is reported to originate from mesenchymal stem cells. ${ }^{8}$ Growth arrest and spontaneous improvement of this tumor have also been observed; 9,10 however, the local recurrence rate accounts for $27 \%$ to $77 \%$ of cases, ${ }^{2,11}$ and aggressive therapy is indispensable for refractory cases. Radical curative resection of the tumor is reported to be the gold standard therapy, ${ }^{12}$ but this approach may be impossible in cases of IAF due to the proximity of eloquent neurovascular structures. ${ }^{2,13,14}$ The effectiveness of radiotherapy and chemotherapy have also been described ${ }^{15}$ but IAF can exhibit a clinically malignant course.

In this report, the authors present an autopsy case of intractable IAF arising exclusively in the sella turcica and discuss its therapeutic strategy.

\section{Illustrative Case}

A 22-year-old otherwise healthy woman presented to our institute with left painful ophthalmoplegia. No specific family history was reported. Magnetic resonance imaging (MRI) revealed the presence of a left extraaxial sellar tumor $(15 \times 8 \mathrm{~mm}$ in size) with cavernous sinus invasion. The tumor was markedly hypointense on T2-weighted imaging (T2WI) and slightly hypointense on T1-weighted imaging (T1WI) relative to the pituitary gland (Fig. 1A-D). At the first examination, no enhancement with gadolinium was noted on T1WI (Fig. 1E and F). No abnormal data were initially observed in endocrine examinations.

Two months after the referral to our department, endoscopic transsphenoidal surgery was performed. The lesion was elastic and hard and had a slightly clear margin between the pituitary and mass, but it was strongly adhered to the left cavernous sinus, hampering resection. As a result, bleeding from the left internal carotid artery (ICA) was encountered, and hemostasis was performed with hemostatic agents. The postoperative course was uneventful, but MRI revealed only partial resection of the tumor (Fig. 1G), and follow-up angiography revealed pseudoaneurysm at the left cavernous portion of the ICA. Coil embolization was additionally performed (data not shown).

At the first pathological examination, an inflammatory myofibroblastic tumor (allergic granulomatosis) was suspected, and steroid pulse therapy was introduced but was ineffective. After a few months, the patient complained of headache, impaired left visual acuity, painful ophthalmoplegia, trigeminal neuralgia, diabetes 

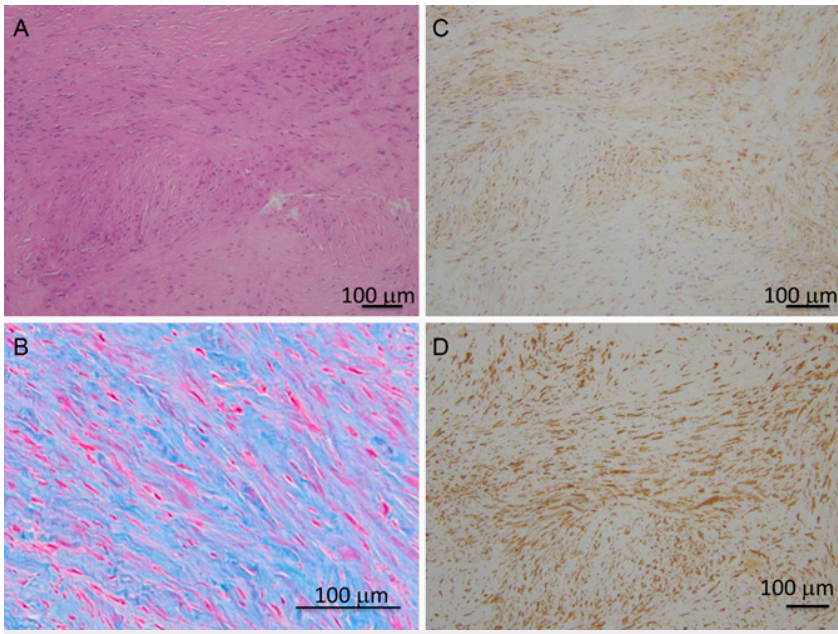

FIG. 2. Histopathological findings of the biopsy specimens. Fibrous connective tissue $(\mathbf{A})$ with collagen fibers $(\mathbf{B})$ is observed. Immunostaining reveals positive reactivity of vimentin (C) and $\alpha$ SMA (D). A: Hematoxylin and eosin stain; original magnification, $\times 100$. B: Azan stain; original magnification, $\times 200$. C and D: Immunostaining; original magnification, $\times 100$. Bars indicate $100 \mu \mathrm{m}$.

insipidus, and panhypopituitarism. MRI revealed the tumor recurrence, with the lesion now gradually enhanced with gadolinium on T1WI (Fig. $1 \mathrm{H}$ and I). Hormone replacement therapy was started. Kaufmann treatment had been introduced for hypophysial amenorrhea but was stopped due to tumor progression.

A pathological consultation and review were performed. A histopathological examination showed fibrous connective tissue with collagen fibers (Fig. 2A and B). Immunostaining revealed positive reactivity of vimentin and $\alpha$-smooth muscle actin (SMA) (Fig. 2C and D). The patient's Ki-67 index was 5\%. No immunostaining was observed for $\beta$-catenin, estrogen, or progesterone. The tumor was diagnosed as IAF.

Gamma Knife radiosurgery (marginal dose 15 Gy, maximum dose $30.1 \mathrm{~Gy}$ ) was performed, and chemotherapy with tamoxifen and sulindac was introduced 17 and 18 months, respectively, after the onset; however, the lesion progressed thereafter. Her visual acuity was lost, and her activities of daily living gradually decreased. Psychological palliative care was introduced.

She was admitted due to a syncope attack caused by ventricular tachycardia (torsades de pointes), but the definite cause was unclear. Transiently, tamoxifen was stopped, and an antiarrhythmic drug was introduced.

Thirty-one months after the onset, she was referred to our department due to consciousness disturbance. MRI revealed hypothalamic invasion of the tumor and perifocal edema, which were suspected of being the cause of her consciousness disturbance (Fig. $3 \mathrm{~A}$ and $\mathrm{B}$ ). Right ICA stenosis, left ICA occlusion, and stroke in cerebral hemispheres were observed on serial MRI

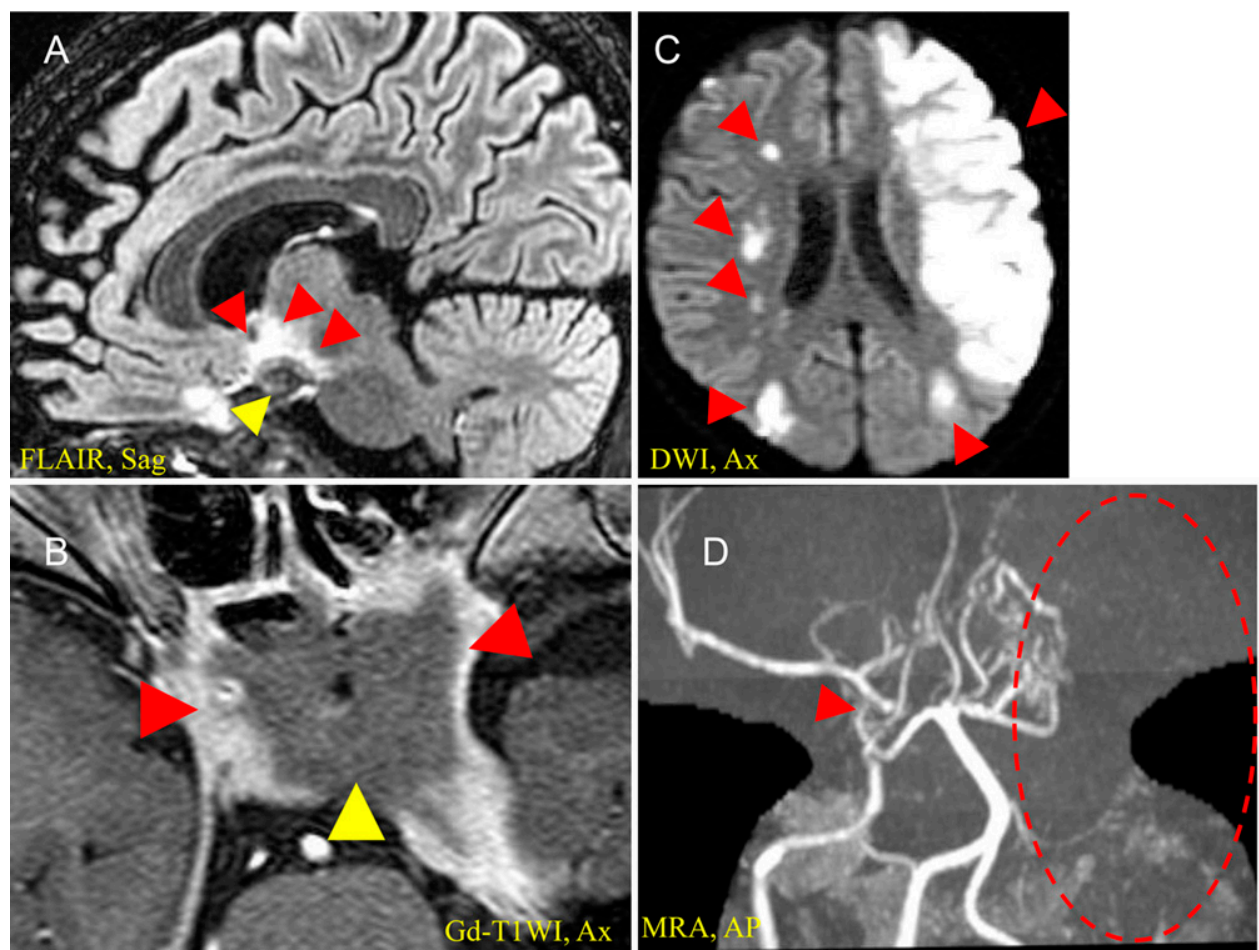

FIG. 3. MRI at the last admission. A: Sagittal fluid-attenuated inversion recovery imaging reveals hypothalamic invasion of the tumor (yellow arrowhead) and perifocal edema (red arrowheads). B: Axial T1WI with gadolinium shows an enlargement of the ring-enhanced tumor (yellow arrowhead) and its invasion to bilateral cavernous sinuses (red arrowheads). C: Diffusion-weighted imaging shows hyperintensity cerebral stroke lesions in both cerebral hemispheres (red arrowheads). D: Anterior-to-posterior view of magnetic resonance angiography shows right ICA stenosis (red arrowhead) and left ICA occlusion at the cavernous portion (red dotted circle). $A P=$ anteroposterior view; $A x=$ axial; Sag = sagittal. 

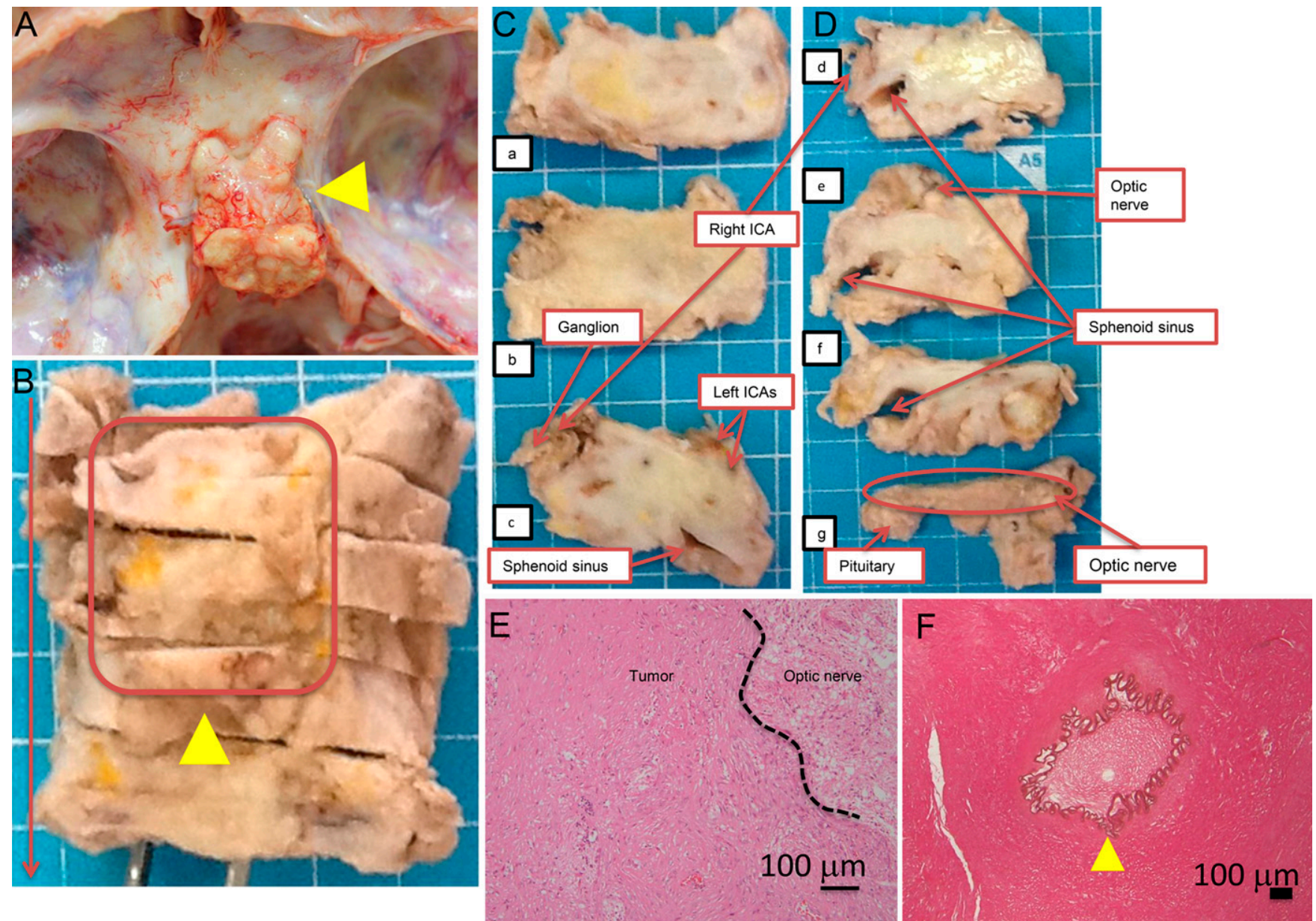

FIG. 4. The autopsy images. The background grid indicates $5 \mathrm{~mm}$. A: The rostral-to-caudal $(\mathrm{RC})$ aspect of the suprasellar region. The brain is almost totally removed except for the tumor-infiltrated structures (yellow arrowhead). B: Anteroposterior (AP) cutting of the tumor from the RC view, arranged in the direction of the red arrow. The anterior part of the optic chiasm has been cut (red square). The yellow arrowhead indicates the posterior side of the optic chiasm. C and D: A coronal section of the tumor, placed in the AP order (a-g). The captions indicate anatomical structures. E: A myofibroblastic tumor with collagenous fiber deposition around the optic nerve. The dotted line indicates the margin of the optic nerve. F: The left ICA is occluded by the tumor (yellow arrowhead). D: Hematoxylin and eosin stain; original magnification, $\times 100$. E: Elastica van Gieson stain; original magnification, $\times 100$. Bars indicate $100 \mu \mathrm{m}$.

(Fig. $3 \mathrm{C}$ and D). Palliative care was applied, and she died 32 months after the onset.

\section{Autopsy Report}

A grayish white hard tumor, $22 \times 20 \times 13 \mathrm{~mm}$ in size, was observed from the optic chiasm and sella turcica to the cavernous sinus (Fig. 4A-C). It involved the optic nerve and compressed the pituitary gland (Fig. 4B-D). Histopathologically, the tumor showed bundles of spindle cells with apparent collagenous fiber deposition (Fig. 4D). Immunostaining demonstrated positive reactivity of vimentin and partial positivity for $\alpha$ SMA. Immunostaining of S100 protein and CD34 was not observed. At the margin, the tumor had invaded the surrounding structures. Tumor cells were found to have infiltrated the pituitary gland and the submucosa of the sphenoid sinus. The optic nerves had been almost completely replaced by the tumor. The ICAs were compressed and suspected of having stenosis and/or occlusion (Fig. 4E). The final diagnosis was as follows: (1) aggressive intracranial fibromatosis in the sella turcica, optic nerve, pituitary gland, sphenoid bone, cavernous sinus, and sphenoidal sinus; (A) cavernous sinus syndrome; (B) panhypopituitarism; (C) diabetes insipidus; (D) occlusion or stenosis of left and right ICAs; (a) ischemic brain and multiple small infarctions, cerebrum and cerebellum; (E) cerebellar tonsillar herniation; (a) cerebral softening, midbrain and brainstem; (2) acute bronchopneumonia, left lower, right middle, and right lower lungs; (3) steroid-induced cortical atrophy of adrenal glands; and (4) steroid-induced hypocellular bone marrow.

\section{Discussion \\ Observations}

IAFs involving the sella turcica are extremely rare; the available cases are summarized in Table 1. ${ }^{2,13,14}$ The MRI features of IAF were first described by Flacke et al. ${ }^{16}$ Marked hypointensity on T2WI and slight hypointensity on T1WI were described in that report. Many authors have similarly reported well-enhanced radiological images; $2,13,14,16$ however, some authors have reported hypoenhanced lesions on angiography. ${ }^{7}$ In our case, the tumor 
TABLE 1. Primary intracranial aggressive fibromatosis involving sella turcica

\begin{tabular}{|c|c|c|c|c|c|c|}
\hline Authors \& Year & Age (yrs), Sex & Onset Symptoms & Surgery & Rx (Gy) & Chemo & Outcome \\
\hline Jenny et al., $2002^{13}$ & $48, F$ & $\begin{array}{c}\text { Headache } \\
\text { Trigeminal neuralgia }\end{array}$ & $\begin{array}{l}\text { TS/partial } \\
\text { resection }\end{array}$ & None & None & $\begin{array}{c}\text { Unknown } \\
\text { (watch and wait policy) }\end{array}$ \\
\hline Gursoy et al., $2005^{14}$ & $34, \mathrm{M}$ & $\begin{array}{l}\text { Panhypopituitarism } \\
\text { Diabetes insipidus } \\
\text { Facial palsy }\end{array}$ & $\begin{array}{l}\text { Transcranial/partial } \\
\text { resection }\end{array}$ & None & None & $\begin{array}{c}\text { Unknown } \\
\text { (watch and wait policy) }\end{array}$ \\
\hline $\begin{array}{l}\text { Inácio de Tella et al., } \\
2006^{2}\end{array}$ & $20, F$ & $\begin{array}{c}\text { Proptosis } \\
\text { Nasal obstruction }\end{array}$ & $\begin{array}{l}\text { Craniofacial/total } \\
\text { resection }\end{array}$ & None & None & $\begin{array}{c}\text { Relapse in } 8 \text { mos } \\
\text { TS partial resection } \\
\text { Unknown (not described) }\end{array}$ \\
\hline Present case & $22, \mathrm{~F}$ & Painful ophthalmoplegia & $\begin{array}{l}\text { TS/partial } \\
\text { resection }\end{array}$ & SRS, 15 Gy & $\begin{array}{l}\text { Tamoxifen and } \\
\text { Sulindac }\end{array}$ & Dead in 32 mos \\
\hline
\end{tabular}

Chemo = chemotherapy; $\mathrm{Rx}=$ radiation; SRS = stereotactic radiosurgery; $\mathrm{TS}=$ transsphenoidal .

had not been enhanced on initial T1WI with gadolinium, but enhancement was later found in a serial MRI examination, suggesting that neoangiogenesis gradually occurred during the tumor growth. Changes in the enhancement profile on radiological images can happen in IAF. The tumor also arose exclusively in the sella turcica and cavernous sinus in the present case, supporting the dural origin of this myofibroblastic tumor. When IAFs arise in this region, resection is anatomically limited, and endocrinological consideration should be practiced when testing abnormalities of the hypothalamic-pituitary axis.

Because of the scarcity of cases and diversity of differential diagnoses, the histopathological diagnosis of IAF is extremely difficult. The differential diagnosis of IAF should include meningioma, schwannoma, cranial fasciitis of childhood, cranial infantile myofibromatosis, ${ }^{4}$ nodular fasciitis, ${ }^{2}$ low-grade fibrosarcoma of bone or meninges, solitary fibrous tumor/hemangiopericytoma, ossifying fibrosarcoma, fibrous dysplasia, ${ }^{13}$ and granulomatous hypophysitis. ${ }^{14}$ At first, we accepted the initial diagnosis of the inflammatory myofibroblastic tumor but later ruled it out due to the progressive clinical course. Retrospectively, the uniform myofibroblastic cells in the abundant collagenous stroma and bundle-like arrangement indicated IAF. ${ }^{4}$ The Ki- 67 index of $5 \%$ implied the serial progression of the lesion. If immunostaining for $\beta$-catenin had been positive, it might have facilitated our initial diagnosis.

The possibility of growth arrest and spontaneous improvement of the tumors should be considered; 9,10 however, the local recurrence rate was reported to be $27 \%-77 \%,{ }^{2,11}$ and a clinically malignant course has been observed in some patients with aggressive fibromatosis. The gold standard therapy is reported to include radical curative resection of the tumor, but such an approach is practically impossible for cases of IAF due to the need to protect eloquent neurovascular structures. A similar situation is found in the field of abdominal surgery as well as other related fields. A curative resection margin tends to be difficult to achieve in cases of FAP-related abdominal aggressive fibromatoses. The functional preservation of the musculoskeletal system is also important. The $\operatorname{pros}^{17-19}$ and cons ${ }^{20-23}$ of the curative radical surgery are still being discussed. IAFs have only been anecdotally described, as reviewed by De Vloo et al., ${ }^{24}$ and maximum safe resection with or without adjuvant therapy seems to be the most realistic operative strategy for IAF. ${ }^{12,13,24}$
Radiotherapy is not always effective for residual lesions. Nuyttens et al. $^{25}$ reported a meta-analysis of radiation therapy. They found that resection and irradiation yielded the best results and that irradiation alone was superior to resection alone. The current recommendation is $56 \mathrm{~Gy}$ in 28 fractions, based on data from the European Organisation for Research and Treatment of Cancer. $^{12,15,26}$ Stereotactic radiosurgery for IAF was described in the present report but was ineffective. The optimum method for the adequate delivery of irradiation remains to be determined.

Medication and chemotherapy are not always effective for residual lesions. We selected a nonsteroidal anti-inflammatory drug (NSAID) and an antihormonal drug as chemotherapeutic agents. The epidemiological female predominance implies a link between aggressive fibromatosis and sex hormones, and such therapy has been applied to this tumor. NSAIDs have been described as anti- $\beta$-catenin drugs. A systematic review by Bocale et al. $^{27}$ described an overall response rate of $51 \%$, and Quast et al. $^{28}$ reported long-term local control with estrogen receptor modulators and NSAIDs in $81 \%$ of cases. This therapy was ineffective for the present patient. In this context, Kaufmann therapy might have been harmful to our patient, although this is mere anecdotal speculation and requires further inspection.

Other chemotherapeutic agents have been anecdotally applied to treat IAF. ${ }^{16,24,29,30}$ Chemotherapeutic agents such as low-dose vinblastine and methotrexate or tyrosine kinase inhibitors (TKIs) may be applicable to $I A F,{ }^{15,30}$ but no reports have yet described their efficacy.

\section{Lessons}

Radical curative resection of IAF can be impossible. Radiotherapy and chemotherapy are not always effective for residual lesions. The appropriate adjuvant therapy for refractory IAF remains to be determined.

Several limitations to this study warrant mention. First, the definite cause of the patient's ventricular tachycardia was not determined by the autopsy. Second, other chemotherapeutic agents, including methotrexate, vinblastine, and TKIs, might have been effective in our patient; however, we were unable to administer these agents due to their toxicity and/or lack of availability. Furthermore, the timing of additional chemotherapy was lost due to the unexpectedly rapid progression of the disease. Third, tamoxifen and sulindac should not have been used for the patient, based on her 
negative findings on immunostaining of estrogen and progesterone and the negative nuclear accumulation of $\beta$-catenin, but there were no other available options for therapy. Finally, IAF is an off-label use of tamoxifen and sulindac in Japan.

\section{Acknowledgments}

Masahiro Tokuda and Takao Ando were attending physicians. Munehiro Ohtsuka, Tetsuya Umeno, and Ayumi Debata were attending neurosurgeons. Interventional neuroradiology was performed by Gohei So, Nobutaka Horie, and Kentaro Hayashi. Gamma Knife radiosurgery was performed by Katsuharu Mori. This work was supported in part by grants-in-aid for scientific research from the Ministry of Education, Culture, Sports, Science and Technology of Japan (JSPS KAKENHI 17K10869 [T.M.], 21 K09154 [K.U.], 21 K09129 [T.M.]).

\section{References}

1. Batsakis JG, Raslan W. Extra-abdominal desmoid fibromatosis. Ann Otol Rhinol Laryngol. 1994;103(4 Pt 1):331-334.

2. Inácio de Tella O Jr, Silva LRF, Stavale JN, Herculano MA, de Paiva Neto MA, Agner C. Aggressive intracranial fibromatosis: case report. Arq Neuropsiquiatr. 2006;64(2B):516-519.

3. Mitchell A, Scheithauer BW, Ebersold MJ, Forbes GS. Intracranial fibromatosis. Neurosurgery. 1991;29(1):123-126.

4. Louis DN, Ohgaki H, Wiestler OD, Cavenee WK, eds. WHO Classification of Tumours of the Central Nervous System. Rev. 4th ed. International Agency for Research on Cancer; 2016.

5. Crago AM, Chmielecki J, Rosenberg M, et al. Near universal detection of alterations in CTNNB1 and Wnt pathway regulators in desmoid-type fibromatosis by whole-exome sequencing and genomic analysis. Genes Chromosomes Cancer. 2015;54(10):606-615.

6. Lazar AJ, Tuvin D, Hajibashi S, et al. Specific mutations in the $\beta$-catenin gene (CTNNB1) correlate with local recurrence in sporadic desmoid tumors. Am J Pathol. 2008;173(5):1518-1527.

7. Dolman CL, Crichton JU, Jones EA, Lapointe J. Fibromatosis of dura presenting as infantile spasms. J Neurol Sci. 1981;49(1):31-39.

8. Wu C, Amini-Nik S, Nadesan P, Stanford WL, Alman BA. Aggressive fibromatosis (desmoid tumor) is derived from mesenchymal progenitor cells. Cancer Res. 2010;70(19):7690-7698.

9. Nakayama T, Tsuboyama T, Toguchida J, Hosaka T, Nakamura T. Natural course of desmoid-type fibromatosis. J Orthop Sci. 2008;13(1):51-55.

10. Fiore M, Rimareix F, Mariani L, et al. Desmoid-type fibromatosis: a front-line conservative approach to select patients for surgical treatment. Ann Surg Oncol. 2009;16(9):2587-2593.

11. Perez-Cruet MJ, Burke JM, Weber R, DeMonte F. Aggressive fibromatosis involving the cranial base in children. Neurosurgery. 1998;43(5):1096-1102.

12. Janssen ML, van Broekhoven DL, Cates JM, et al. Meta-analysis of the influence of surgical margin and adjuvant radiotherapy on local recurrence after resection of sporadic desmoid-type fibromatosis. $\mathrm{Br}$ J Surg. 2017;104(4):347-357.

13. Jenny B, Kaye AH, Gonzales MF. Aggressive intracranial fibromatosis: case report. J Clin Neurosci. 2002;9(4):450-453.

14. Gursoy A, Cesur M, Aktaş B, et al. Intracranial aggressive fibromatosis presenting as panhypopituitarism and diabetes insipidus. Pituitary. 2005;8(2):123-126.

15. Kasper B. Systemic treatment approaches for sporadic desmoidtype fibromatosis: scarce evidence and recommendations. Oncol Res Treat. 2015;38(5):244-248.
16. Flacke S, Pauleit D, Keller E, et al. Infantile fibromatosis of the neck with intracranial involvement: MR and CT findings. AJNR Am J Neuroradiol. 1999;20(5):923-925.

17. Spear MA, Jennings LC, Mankin HJ, et al. Individualizing management of aggressive fibromatoses. Int J Radiat Oncol Biol Phys. 1998;40(3):637-645.

18. Ballo MT, Zagars GK, Pollack A, Pisters PW, Pollack RA. Desmoid tumor: prognostic factors and outcome after surgery, radiation therapy, or combined surgery and radiation therapy. J Clin Oncol. 1999;17(1):158-167.

19. Stoeckle $E$, Coindre JM, Longy $M$, et al. A critical analysis of treatment strategies in desmoid tumours: a review of a series of 106 cases. Eur J Surg Oncol. 2009;35(2):129-134.

20. Merchant NB, Lewis JJ, Woodruff JM, Leung DH, Brennan MF. Extremity and trunk desmoid tumors: a multifactorial analysis of outcome. Cancer. 1999;86(10):2045-2052.

21. Gronchi A, Casali PG, Mariani L, et al. Quality of surgery and outcome in extra-abdominal aggressive fibromatosis: a series of patients surgically treated at a single institution. $J$ Clin Oncol. 2003;21(7):1390-1397.

22. Kasper B, Baumgarten C, Bonvalot $S$, et al. Management of sporadic desmoid-type fibromatosis: a European consensus approach based on patients' and professionals' expertise - a Sarcoma Patients EuroNet and European Organisation for Research and Treatment of Cancer/Soft Tissue and Bone Sarcoma Group initiative. Eur J Cancer. 2015;51(2):127-136.

23. Lev D, Kotilingam D, Wei $C$, et al. Optimizing treatment of desmoid tumors. J Clin Oncol. 2007;25(13):1785-1791.

24. De Vloo P, De Vlieger J, Vander Poorten V, Sciot R, van Loon J, Van Calenbergh F. Desmoid tumors in neurosurgery: a review of the literature. Clin Neurol Neurosurg. 2015;129:78-84.

25. Nuyttens JJ, Rust PF, Thomas CR Jr, Turrisi AT 3rd. Surgery versus radiation therapy for patients with aggressive fibromatosis or desmoid tumors: a comparative review of 22 articles. Cancer. 2000;88(7):1517-1523.

26. Keus RB, Nout RA, Blay JY, et al. Results of a phase II pilot study of moderate dose radiotherapy for inoperable desmoid-type fibromatosis-an EORTC STBSG and ROG study (EORTC 6299122998). Ann Oncol. 2013;24(10):2672-2676.

27. Bocale D, Rotelli MT, Cavallini A, Altomare DF. Anti-oestrogen therapy in the treatment of desmoid tumours: a systematic review. Colorectal Dis. 2011;13(12):e388-e395.

28. Quast DR, Schneider R, Burdzik E, Hoppe S, Moslein G. Longterm outcome of sporadic and FAP-associated desmoid tumors treated with high-dose selective estrogen receptor modulators and sulindac: a single-center long-term observational study in 134 patients. Fam Cancer. 201615(1):31-40.

29. Laufer I, Wolinsky JP, Gokaslan ZL. Desmoid tumors. World Neurosurg. 2013;79(1):97-98.

30. Nishida Y, Tsukushi S, Urakawa H, et al. Low-dose chemotherapy with methotrexate and vinblastine for patients with desmoid tumors: relationship to CTNNB1 mutation status. Int J Clin Oncol. 2015;20(6):1211-1217.

\section{Disclosures}

The authors report no conflict of interest concerning the materials or methods used in this study or the findings specified in this paper.

\section{Author Contributions}

Conception and design: Ujifuku, Kamada, Matsuo. Acquisition of data: Ujifuku, Sadakata, Yoshida, Kamada, Morikawa, Abe, Shimokawa. Analysis and interpretation of data: Ujifuku, Kamada, Abe, Nakazato, Shimokawa. Drafting the article: Ujifuku, Yoshida, Suyama, Shimokawa. Critically revising the article: Ujifuku, Baba, Suyama, Matsuo. Reviewed submitted version of manuscript: 
Ujifuku, Baba, Abe, Suyama. Approved the final version of the manuscript on behalf of all authors: Ujifuku. Administrative/technical/ material support: Sadakata, Shimokawa. Pathological diagnosis: Abe, Nakazato, Shimokawa.

\section{Supplemental Information}

Previous Presentations

Portions of this work were presented in poster form at the annual

meeting of the Japanese Society of Neuro-Oncology, Hiroshima, Japan, November 25, 2012.

\section{Correspondence}

Kenta Ujifuku: Nagasaki University Graduate School of Biomedical Sciences, Nagasaki, Japan. kujifuku-nag@umin.ac.jp. 